\title{
BMJ Open Acute myocardial infarction incidence and survival in Aboriginal and non- Aboriginal populations: an observational study in the Northern Territory of Australia, 1992-2014
}

Cushla Coffey, ${ }^{1}$ Yuejen Zhao ${ }^{10},{ }^{1}$ John R Condon, ${ }^{2}$ Shu Li, ${ }^{1}$ Steven Guthridge ${ }^{2}$

To cite: Coffey C, Zhao Y, Condon JR, et al. Acute myocardial infarction incidence and survival in Aboriginal and non-Aboriginal populations: an observational study in the Northern Territory of Australia, 1992-2014. BMJ Open 2020;10:e036979. doi:10.1136/ bmjopen-2020-036979

- Prepublication history for this paper is available online. To view these files, please visit the journal online (http://dx.doi. org/10.1136/bmjopen-2020036979).

Received 14 January 2020 Revised 20 August 2020 Accepted 25 August 2020

\section{Check for updates}

(c) Author(s) (or their employer(s)) 2020. Re-use permitted under CC BY-NC. No commercial re-use. See rights and permissions. Published by BMJ.

${ }^{1}$ Health Gains Planning, Northern Territory Department of Health, Darwin, Northern Territory, Australia

${ }^{2}$ Menzies School of Health Research, Charles Darwin University, Darwin, Northern Territory, Australia

Correspondence to

Dr Yuejen Zhao;

yuejen.zhao@nt.gov.au

\section{ABSTRACT}

Objectives To examine long-term trends in acute myocardial infarction (AMI) incidence and survival among Aboriginal and non-Aboriginal people.

Design Retrospective cohort study.

Setting, participants All first AMI hospital cases and deaths due to ischaemic heart disease in the Northern Territory of Australia (NT), 1992-2014.

Main outcome measures Age standardised incidence, survival and mortality.

Results The upward trend in Aboriginal AMI incidence plateaued around 2007 for males and 2001 for females. AMI incidence decreased for non-Aboriginal population, consistent with the national trends. AMI incidence was higher and survival lower for males, for Aboriginal people and in older age groups. In 2014, the age standardised incidence was 881 and 579 per 100000 for Aboriginal males and females, respectively, compared with 290 and 187 per 100000 for non-Aboriginal counterparts. The incidence disparity between Aboriginal and non-Aboriginal population was much greater in younger than older age groups. Survival after an AMI improved over time, and more so for Aboriginal than non-Aboriginal patients, because of a decrease in prehospital deaths and improved survival of hospitalised cases.

Conclusions There was an important breakpoint in increasing trends of Aboriginal AMI incidence between 2001 and 2007. The disparity in AMI survival between the NT Aboriginal and non-Aboriginal populations reduced over time as survival improved for both populations.

\section{INTRODUCTION}

Ischaemic heart disease (IHD) is the most common and serious form of cardiovascular disease (CVD) and the leading cause of premature death in Australia. ${ }^{1}$ Acute myocardial infarction (AMI) is one of two major clinical presentations of IHD (the other being angina). IHD disproportionally affects men, older age groups, lower socioeconomic status groups and those living in regional and remote areas. $^{2}$ Australian IHD death rates have been declining since the 1960s,
Strengths and limitations of this study

- This study enables us to monitor key outcome measures in chronic diseases by linking existing computerised clinical and administrative data collections for health service evaluation.

- This study contains a large Aboriginal population using linked data over a 23-year period.

- This study compared acute myocardial infarction incidence trends with the national data.

- Our findings for the Northern Territory of Australia Aboriginal population may not be generalisable to the wider Aboriginal population across Australia.

although mortality levels and rates of decline have varied between population subgroups. ${ }^{3}$

Aboriginal and Torres Strait Islander people (hereafter respectfully referred to as Aboriginal people) have rates of IHD many times higher than non-Aboriginal Australians. ${ }^{1}$ Approximately $10 \%$ of Aboriginal Australians live in the Northern Territory of Australia (NT), a large and sparsely populated area in northern and central Australia, where Aboriginal people comprise $30 \%$ of the population (compared with $1 \%-5 \%$ in other states and territories). ${ }^{4}$ The NT has had high-quality health data for Aboriginal people for several decades, which enables examination of long-term trends that is not possible elsewhere in Australia. In a previous NT study ${ }^{5}$ AMI incidence declined between 1992 and 2004 for the non-Aboriginal population, but increased by about $50 \%$ for the Aboriginal population; survival after an AMI was lower for Aboriginal than non-Aboriginal patients and although survival after an AMI improved for both, the improvement was less for Aboriginal than non-Aboriginal people.

Since 2004, improvements in detection, medical and surgical treatment of IHD and 
reduction in risk factor levels have occurred. ${ }^{6}$ In Australia, the incidence of AMI fell by $66 \%$ between 2007 and 2014, with a similar decline for men and women. ${ }^{2}$ The aim of this study was to examine recent trends in AMI incidence and survival among Aboriginal and non-Aboriginal patients in the NT, examine contributing factors and estimate any disparities between populations.

\section{METHODS}

This was a retrospective observational study that linked hospital inpatient and death data to ascertain first AMI events occurring in adult NT residents (aged $\geq 20$ years) between 1 January 1992 and 31 December 2014 and to estimate AMI incidence and survival after an AMI.

AMI events were ascertained using three data sources: NT public hospital inpatient data, NT Registry of Births, Deaths and Marriages (BDM) data and the National Death Index (NDI) data. International Classification of Disease (ICD) was used to identify AMI cases with a code ICD-9 410.*/ICD-10 I21.* in both principal and secondary diagnoses and hospital length of stay $>2$ days, or death from IHD. Data linkage and clerical review were applied on names, sex, date of birth, date of death and residential address to link hospitalisations and death at patient level (the data process flowchart is available as online supplemental file). Indigenous status (Aboriginal or non-Aboriginal) was obtained from the hospital inpatient data. NT hospitals record Indigenous status for all clients using the national standard classification; ${ }^{8}$ these data have previously been estimated to be $98 \%$ accurate. $^{9}$ Indigenous status was not used for data linkage.

Three primary AMI outcomes were measured: incidence, prehospital death and survival. The first AMI episode was ascertained by using an 18-month clearance period; persons with an AMI hospitalisation in the 18 months before the study commencement date (1 January 1992) were excluded. Second and subsequent AMI episodes during the study period were excluded in incidence estimation. Cause of death was recorded in BDM data as uncoded text. A keyword search was performed for all death registrations to ascertain IHD deaths occurring in the NT. Consistent with other reports, ${ }^{210}$ an expanded list of keywords was used to identify IHD deaths. ${ }^{11}$ The keywords used to select potential AMIs included infarct, ischaemia, coronary, myocardial, cardiac, angina, ventricular, tachycardia and fibrillation. The first AMI hospitalisations and IHD deaths were linked to identify first AMI events, whether treated in hospital or died without hospitalisation. The combined dataset was then matched to the NDI to identify people hospitalised for AMI in the NT who died in other Australian states or territories. The coded cause of death was then used to distinguish IHD from non-IHD deaths using expanded IHD codes (ICD-9 410.*-414.*, ICD-10 I20.*-I25.*). AMI deaths with no record of a prior hospitalisation for AMI were classified as prehospital deaths. Survival time for hospitalised AMI patients who died from IHD was calculated as the date of death minus index hospitalisation admission date. The survival time was assumed to be 0.5 days for individuals who died without hospitalisation or with a same-day hospitalisation. Survival time was censored at date of nonIHD death or the separation date of last hospitalisation (if discharged alive).

Mean, median, ratio and proportion with Pearson's $\chi^{2}$ test were used for descriptive and comparative analysis. Age standardised incidence rate was based on the NT estimated resident population by year, 5-year age group, sex, Indigenous status and remoteness. ${ }^{4}$ Australian population (2001) was used for age standardisation. The ratios of age-standardised mortality rate and incidence rate were compared as an indirect approximation of survival (case fatality). Joinpoint analysis was used to detect potential breakpoints in incidence trends. Negative binomial regression was chosen for multivariable analysis to estimate incidence rate ratio (IRR) due to data overdispersion. Logistic regression was used to estimate ORs for prehospital death. Cox regression was used to estimate HRs and AMI-specific mortality in survival analysis. Data were available for the following explanatory variables: date and age at first AMI episode or death; sex; Indigenous status; and remoteness of residence classified as urban (Darwin, Alice Springs and their hinterlands) or remote (the rest of the NT).

All statistical analyses were performed using Stata (Special Edition V.15.1, StataCorp).

\section{Patient and public involvement}

No patient involved.

\section{RESULTS}

Of the 6926 first AMI cases between 1992 and 2014, 69\% were men and $44 \%$ were Aboriginal people (table 1). Cases for the Aboriginal cohort were younger (median age 48 vs 60 years for men; 52 vs 70 for women) and more likely to reside in remote areas $(73 \%$ vs $17 \%)$ than the non-Aboriginal cohort. Twenty-one per cent of AMI cases died without hospitalisation, in both the Aboriginal and non-Aboriginal cohorts.

The age-standardised AMI incidence rate was 593 per 100000 for Aboriginal and 308 for non-Aboriginal people (table 2). The rates were higher for men and remote residents. Higher AMI age-specific incidence rates for Aboriginal people were observed across all age groups except for persons aged $\geq 70$ years, where nonAboriginal rates exceeded Aboriginal by $19 \%(\mathrm{p}<0.05)$. In persons aged 20-39 years, the disparity between Aboriginal and non-Aboriginal rates was the highest, nearly nine times $(p<0.05)$. Between 1992 and 2014, AMI incidence increased in the NT Aboriginal population by 1.9 times for males and 3.7 times for females (figure 1). The upward trends in the Aboriginal population appeared to plateau around 2007 in males and 2001 in females (both $\mathrm{p}<0.001)$. The slopes after breakpoint were negative but statistically non-significant (male -3.0 per year, $\mathrm{p}=0.86$; 
Table 1 Demographic characteristics of people with a first-ever acute myocardial infarction, Northern Territory, 1992-2014

\begin{tabular}{|c|c|c|c|c|}
\hline & Aboriginal & Non-Aboriginal & $P$ value & Total \\
\hline Cases, $\mathrm{n}(\%)^{*}$ & $3022(44)$ & $3904(56)$ & $<0.001$ & $6926(100)$ \\
\hline Men, n (\%) & $1840(61)$ & $2911(75)$ & $<0.001$ & $4751(69)$ \\
\hline Men & 48 & 60 & $<0.001$ & 55 \\
\hline Women & 52 & 70 & $<0.001$ & 59 \\
\hline Mean acute myocardial infarction follow-up (years) $†$ & 15 & 16 & 0.030 & 16 \\
\hline Prehospital deaths, n (\%) & $621(21)$ & $802(21)$ & 0.995 & $1423(21)$ \\
\hline Ischaemic heart disease deaths, n (\%) & $676(22)$ & $954(24)$ & 0.044 & $1630(24)$ \\
\hline Total deaths, n (\%) & $1624(54)$ & $1960(50)$ & 0.004 & $3584(52)$ \\
\hline
\end{tabular}

${ }^{*}$ Null hypothesis: case proportion equal to population proportion (Aboriginal 30\%).

†Likely underestimated.

female -3.1 per year, $\mathrm{p}=0.66)$. The Aboriginal agespecific incidence increased faster in younger age groups (figure 2). Age-standardised AMI incidence for the nonAboriginal population decreased by $36 \%$ and $28 \%$ for males and females respectively, (figure 1); these reductions were only evident in older age groups (figure 2). The age-standardised AMI mortality rate was $67 \%$ higher (rate ratio $1.67,95 \%$ CI 1.48 to 1.88 ) for Aboriginal than non-Aboriginal people, and higher for men and remote residents (table 3 ). In the total NT population (Aboriginal and non-Aboriginal combined), the ratio between age-standardised mortality and incidence rate was 0.29 , diminishing over time but generally increasing with age except for the youngest patients (aged 20-39 years).

When adjusted for other factors (table 4), AMI incidence was 3.1 times higher for Aboriginal people, 2.1 times higher for males. For Aboriginal people, AMI incidence increased with age by $5 \%$ per year and increased over time by $3 \%$ per year of diagnosis. The risk of AMI incidence was $12 \%$ higher in remote areas. For nonAboriginal people, AMI incidence significantly increased with age by $9 \%$ per year and decreased over time by $1 \%$ per year and the risk of AMI incidence was 30\% higher in remote areas. The actual Aboriginal:non-Aboriginal

Table 2 Age-standardised and age-specific incidence rates per 100000 population and rate ratios (95\% Cls) of acute myocardial infarction, Northern Territory, 1992-2014

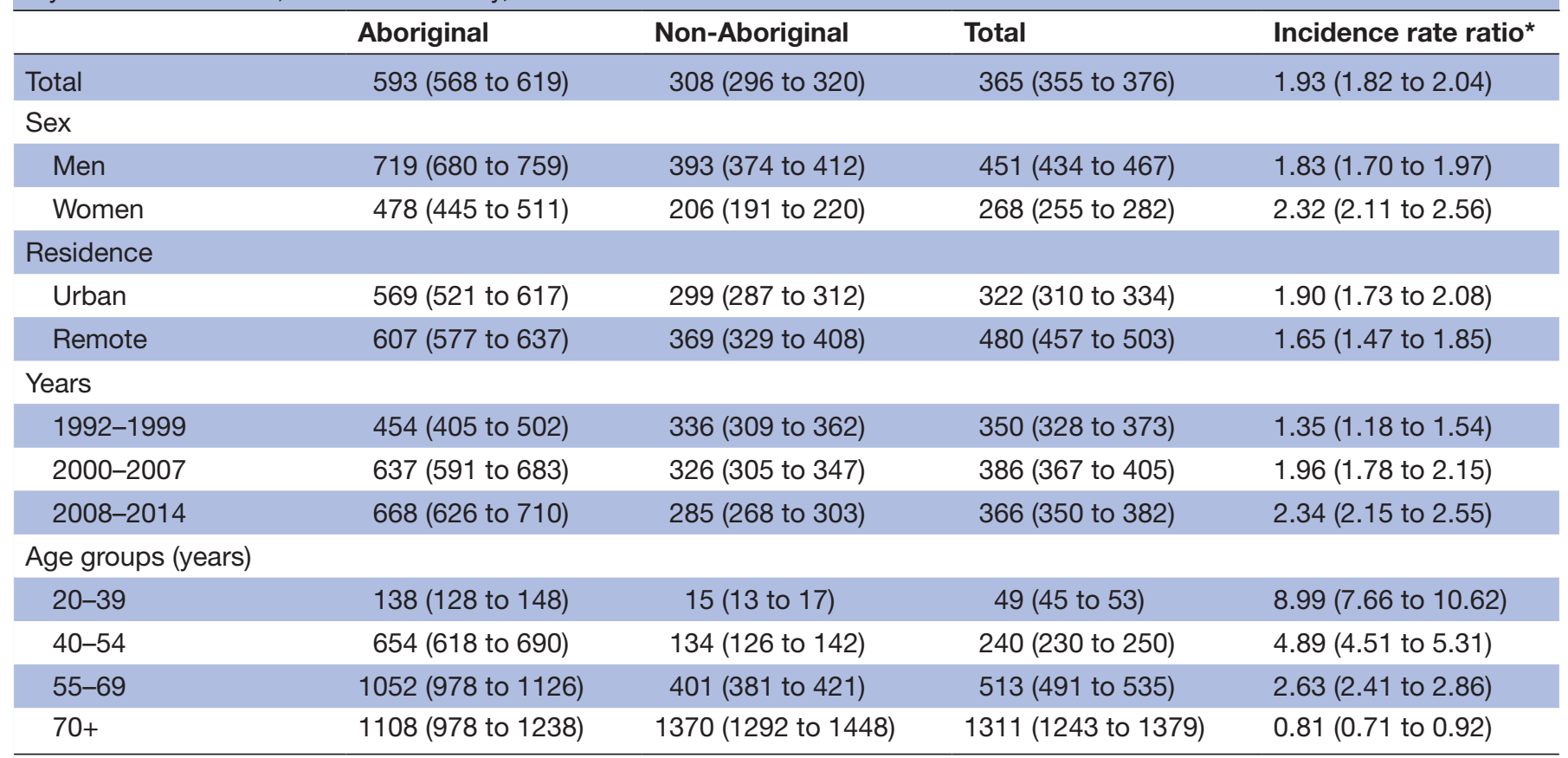

${ }^{*}$ Aboriginal versus non-Aboriginal. 

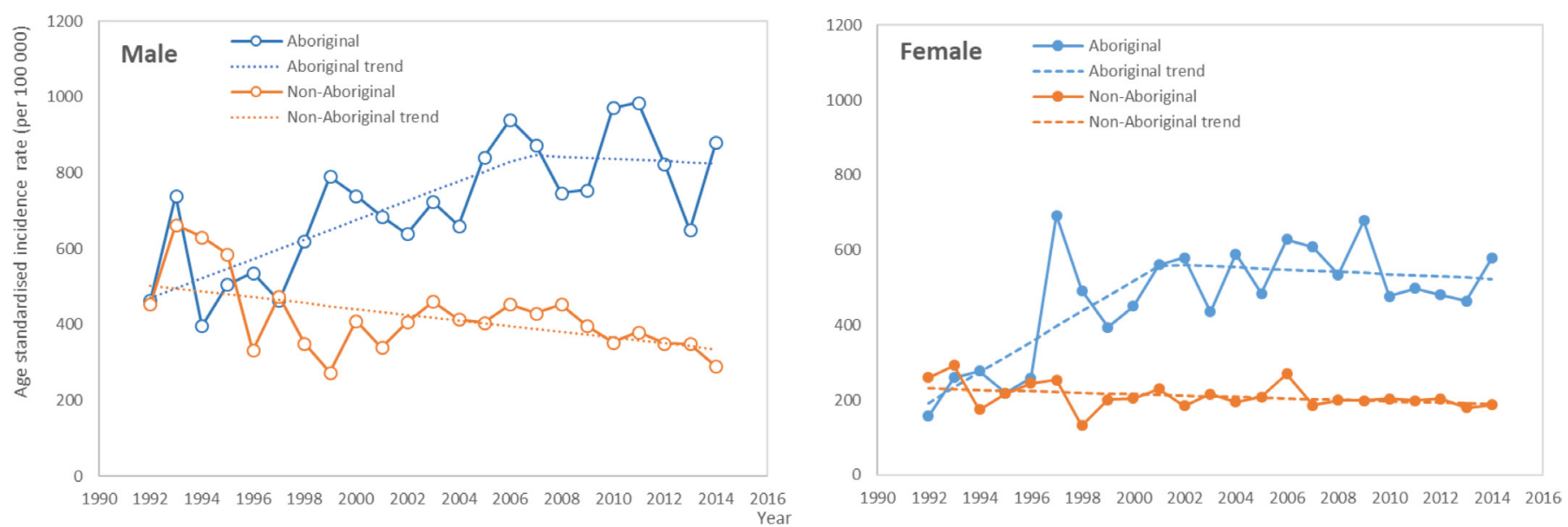

Figure 1 Incidence of acute myocardial infarction and joinpoint trend analysis in populations aged $\geq 20$ years by sex and Aboriginal status, Northern Territory, 1992-2014 (Note: Incidence rate was age standardised to the 2001 Australian population).

IRR was higher in younger than older age group and increased over time in all age groups (table 5).

Multivariable analysis of prehospital deaths indicated that prehospital death was more common for males and for Aboriginal people but decreased over time more for Aboriginal than non-Aboriginal people (table 4). For non-Aboriginal people, prehospital death increased with age, was more common for remote than urban residents, and less common in later years. However, the proportions of Aboriginal people who died without hospital admission were similar between remote and urban areas $(\mathrm{OR}$ $0.98,95 \%$ CI 0.80 to 1.20 ).

For hospital cases, there were no statistically significant differences (as indicated by HR) in mortality between Aboriginal and non-Aboriginal patients, between males and females and between remote and urban residents (table 4). The mortality increased by $7 \%$ per year of age for non-Aboriginal patients but by only $4 \%$ for Aboriginal patients, and decreased by $7 \%-8 \%$ per year over time for both Aboriginal and non-Aboriginal AMI patients $(\mathrm{p}<0.001)$.

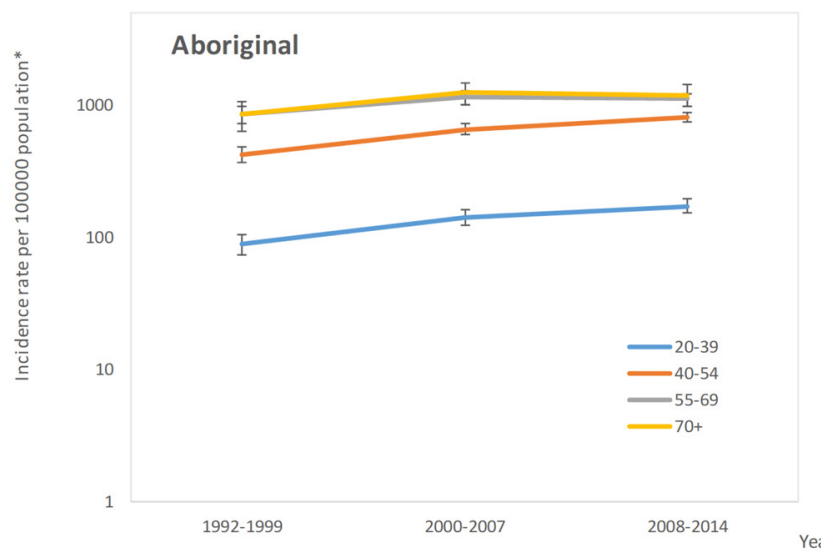

For all-case AMIs (ie, prehospital deaths plus hospitalised cases), the mortality was $38 \%$ higher for Aboriginal people and $33 \%$ higher for males (table 4). Non-Aboriginal patients were $23 \%$ more likely to die in remote areas, whereas there was no difference in survival by remoteness for Aboriginal people. Mortality increased by $2 \%-3 \%$ per year of age. There were significant improvements in all-case survival over years of diagnosis, which was more pronounced for Aboriginal than non-Aboriginal patients.

\section{DISCUSSION}

Between 1992 and 2014, AMI incidence increased by about $50 \%$ for the NT Aboriginal population, inconsistent with the NT non-Aboriginal and national trends of decreasing incidence. ${ }^{27}$ By 2014, AMI incidence for the NT Aboriginal population was approximately three times that of the NT non-Aboriginal population. However, it is encouraging to see that the upward trend for the Aboriginal population plateaued around 2001-2007, which was consistent with efforts over the previous two

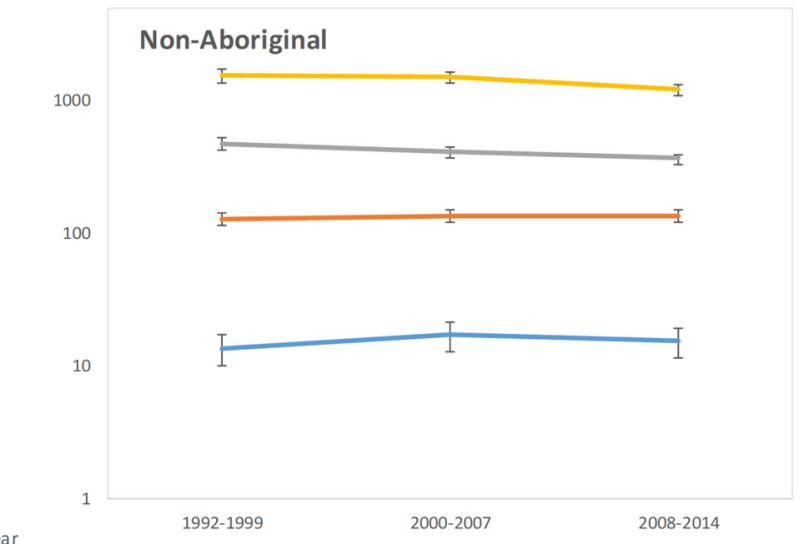

Figure 2 Incidence rate with $95 \% \mathrm{Cl}$ of acute myocardial infarction by age group and Aboriginal status, Northern Territory, 1992-2014. *Logarithm scale was used to assess rate of change. 
Table 3 Age-adjusted and age-specific mortality rates (per 100000$)$ and rate ratios $(95 \% \mathrm{Cl})$ of acute myocardial infarction, Northern Territory, 1992-2014

\begin{tabular}{|c|c|c|c|c|c|}
\hline & Aboriginal & Non-Aboriginal & Total & $\begin{array}{l}\text { Aboriginal vs non- } \\
\text { Aboriginal rate ratio }\end{array}$ & $\begin{array}{l}\text { Mortality/incidence } \\
\text { rate ratio* }\end{array}$ \\
\hline Total & 154 (139 to 168$)$ & 92 (85 to 99$)$ & 104 (98 to 111$)$ & 1.67 (1.48 to 1.88$)$ & 0.29 (0.27 to 0.30$)$ \\
\hline \multicolumn{6}{|l|}{ Sex } \\
\hline Men & 205 (181 to 229) & 121 (110 to 133 ) & 135 (125 to 145$)$ & 1.69 (1.45 to 1.96$)$ & $0.30(0.28$ to 0.33$)$ \\
\hline Women & 108 (90 to 126$)$ & 59 (51 to 67$)$ & 71 (64 to 79 ) & 1.82 (1.47 to 2.24$)$ & 0.27 (0.24 to 0.30$)$ \\
\hline \multicolumn{6}{|l|}{ Residence } \\
\hline Urban & 150 (122 to 178$)$ & 87 (80 to 95$)$ & 92 (85 to 99$)$ & 1.72 (1.40 to 2.08$)$ & $0.29(0.26$ to 0.31$)$ \\
\hline Remote & 156 (139 to 173$)$ & 127 (101 to 152 ) & 137 (123 to 151$)$ & 1.23 (0.99 to 1.55$)$ & 0.29 (0.26 to 0.32$)$ \\
\hline \multicolumn{6}{|l|}{ Years } \\
\hline 1992-1999 & 213 (176 to 251$)$ & 144 (125 to 163$)$ & 155 (139 to 172 ) & 1.48 (1.19 to 1.83$)$ & 0.44 (0.39 to 0.50$)$ \\
\hline 2000-2007 & 172 (146 to 198$)$ & 110 (97 to 123$)$ & 122 (110 to 133$)$ & 1.57 (1.29 to 1.89$)$ & 0.35 (0.31 to 0.39$)$ \\
\hline 2008-2014 & 103 (85 to 122$)$ & 54 (46 to 62$)$ & 64 (57 to 72 ) & 1.91 (1.51 to 2.40 ) & 0.18 (0.16 to 0.21$)$ \\
\hline \multicolumn{6}{|c|}{ Age groups (years) } \\
\hline 20-39 & 29 (23 to 35$)$ & 4 (2 to 6$)$ & 11 (9 to 13$)$ & 8.06 (5.82 to 11.52$)$ & 0.22 (0.19 to 0.26$)$ \\
\hline $40-54$ & 112 (96 to 128$)$ & 23 (19 to 27 ) & 41 (37 to 45$)$ & 4.85 (3.98 to 5.92$)$ & 0.17 (0.15 to 0.19$)$ \\
\hline $55-69$ & 283 (245 to 321$)$ & 84 (74 to 94$)$ & 118 (108 to 128$)$ & 3.39 (2.84 to 4.03 ) & 0.23 (0.21 to 0.25$)$ \\
\hline $70+$ & 395 (317 to 473 ) & 478 (432 to 524$)$ & 459 (419 to 499$)$ & 0.83 (0.66 to 1.02$)$ & 0.35 (0.32 to 0.39$)$ \\
\hline
\end{tabular}

*Ratio of acute myocardial infarction age-standardised mortality rate to incidence rate.

decades to improve primary care and access to specialist cardiac services for NT Aboriginal populations. ${ }^{12}$ This study provided indirect evidence for the effectiveness of primary and specialist care for the remote Aboriginal population. This study suggested that living in remote areas had $12 \%$ and $30 \%$ higher AMI incidence for Aboriginal and non-Aboriginal people, respectively. This higher incidence is in line with the higher rates of IHD risk factors reported in remote areas ${ }^{13}$ but may also be associated with lower access to primary and specialist care. ${ }^{14}$ Higher AMI incidence in remote areas has not been consistently reported with some studies showing higher CVD incidence in remote $\operatorname{areas}^{215}$ and others observing the opposite. ${ }^{516}$ The Western Australia study included a large urban Aboriginal population from Perth, while the previous NT study may have included remote Aboriginal residents who moved to urban areas for complex medical care. ${ }^{516}$

Survival after an AMI was lower for Aboriginal than non-Aboriginal people throughout the study period, primarily because Aboriginal people suffering an AMI were more likely to die before arrival at hospital. Lower survival in Aboriginal people may be explained by a higher prevalence of risk factors, greater burden of chronic disease and significant barriers to necessary cardiovascular services across the care continuum due to the lack of availability, accessibility and cultural appropriateness, with results consistent with national reports and those from other states. ${ }^{116}$ Evidence suggests Aboriginal people have been under-resourced for both primary and specialist care prior to hospitalisation. ${ }^{13}{ }^{14}$ Following discharge from hospital differences occurred in access to, receipt of, management and outcomes from cardiovascular therapies. ${ }^{17-19}$ However, survival after an AMI improved considerably over time for both NT Aboriginal and non-Aboriginal people, similar to national trends. ${ }^{20}$ The improvement was more marked for Aboriginal people. If the modelled trend continues, the AMI survival gap is predicted to be closed by 2022 .

IHD outcome data are important for understanding the AMI burden, exposure to risk factors and the effectiveness of preventative interventions. ${ }^{1}$ Prompt access to primary care is vital to AMI survival, providing timely opportunity for comprehensive treatments including revascularisation, reducing early damage and long-term complications. Access to specialist cardiology services, interventional diagnostics and other acute care modalities are limited for remote residents, who experience significant barriers to necessary services across the continuum of care ${ }^{17-19}$ This study supports evidence for greater and targeted efforts and resources in remote communities to address cardiac health needs. ${ }^{21}$ A selective approach of increasing hospital care without adequate primary care is unlikely to be sufficient to close the CVD survival gap. AMI survival can be improved by better public awareness and responsiveness of health services, advances in early risk assessment and management, and use of antithrombotic, antihypertensive and lipid-lowering drugs. ${ }^{20}$ Investment in NT cardiac services resulted in expansion and improvement of reperfusion and revascularisation treatment, rehabilitation and secondary prevention services. ${ }^{22}$ The coexistence of increased incidence and reduced 


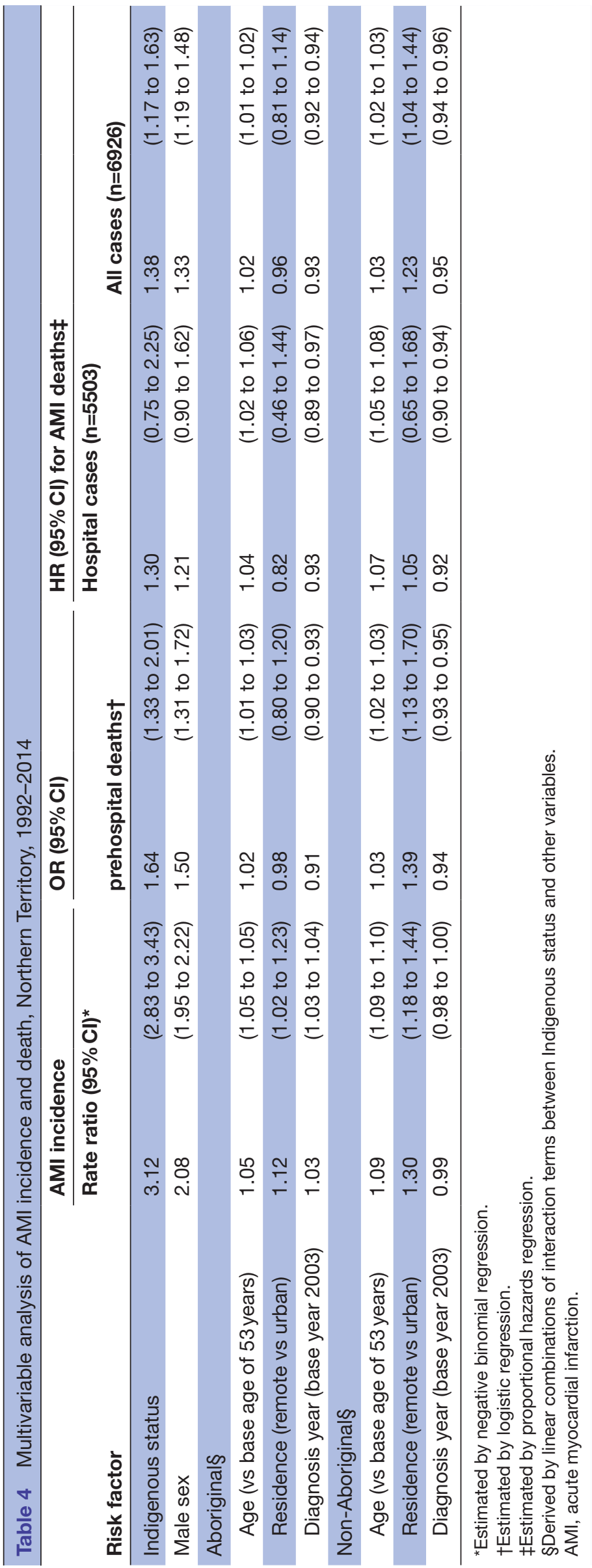

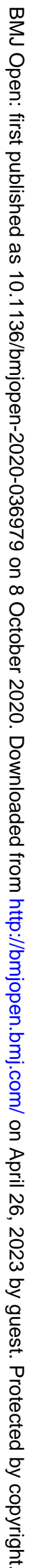


Table 5 Actual acute myocardial infarction Aboriginal versus non-Aboriginal incidence rate ratio (95\% Cl) by ages and years of diagnosis

\begin{tabular}{lllr}
\hline Age in years & $\mathbf{1 9 9 2 - 1 9 9 9}$ & $\mathbf{2 0 0 0 - 2 0 0 7}$ & $\mathbf{2 0 0 8 - 2 0 1 4}$ \\
\hline $20-39$ & $6.61(4.79$ to 9.11$)$ & $8.42(6.40$ to 11.09$)$ & $11.3(8.52$ to 15.00$)$ \\
$40-54$ & $3.25(2.71$ to 3.89$)$ & $4.81(4.19$ to 5.53$)$ & $5.98(5.24$ to 6.84$)$ \\
$55-69$ & $1.80(1.49$ to 2.18$)$ & $2.82(2.43$ to 3.27$)$ & $3.03(2.65$ to 3.47$)$ \\
$70+$ & $0.55(0.42$ to 0.73$)$ & $0.83(0.67$ to 1.03$)$ & $0.99(0.80$ to 1.23$)$ \\
\hline
\end{tabular}

mortality will result in a continuing increase in prevalence and workload for AMI and additional pressure on prevention, diagnosis and cardiac services.

Women had lower AMI incidence than men (consistent with national rates), ${ }^{23}$ and higher survival that was predominantly because of lower prehospital death. This study shows that Aboriginal females had the breakpoint of AMI incidence 5 years earlier than Aboriginal males. Nationally less favourable IHD death trends among men (aged 40-69 years) have been recently reported. ${ }^{20}$ IHD may be under-recognised in females, potentially leading to more advanced disease. ${ }^{24}$

This study provides updated AMI trend data during a period where considerable changes have occurred in primary care and coronary care services in the NT. A strength of this study is that it uses data for a large and reliably identified Aboriginal population study cohort over a 23-year period. Our findings indicate the increasing trend of AMI incidence among NT Aboriginal population has plateaued and may even be starting to decrease, becoming parallel to non-Aboriginal rates. This important result is encouraging and needs to be sustained. There is evidence to suggest that the methodology in this study has improved data quality. ${ }^{25}$ Quality of demographic variables were assessed as highly reliable. ${ }^{9}$

The following limitations need to be considered. First, this study compared AMI incidence trends with national data. $^{2}$ Due to data issues, the methods used by AIHW for national estimates used unlinked data and included unstable angina, which likely overestimated AMI incidence. There were also different case definitions and inclusion criteria (such as $25+$ yearsage cut-off). ${ }^{2}$ With more restrictive definitions applied in this study and NT rates higher than the national incidence, it is likely that the real difference between national and NT rates might be even greater. This potential bias will not affect our conclusion. Second, we did not use 'ever identified' method to enhance Aboriginal population, due to almost nil underidentification of Aboriginal population in the NT. ${ }^{26}$ We used the manual search of AMI deaths in administrative data and data linkage to identify repeated hospitalisations for same individuals to avoid overestimation of incidence. We believed that our approach to AMI case identification was more accurate and robust than the AIHW method. Third, it is still possible that AMI cases were missed in our study, due to interstate deaths, deaths not recorded, misclassified, cases missed by or not presenting at hospital. Our data were considered reasonably complete and covered all hospitals accessible to Aboriginal patients, except one small private hospital. Finally, our finding may not be generalisable to Aboriginal people elsewhere in Australia because of the distinctive features of Aboriginal people in the NT, the majority of whom live in very remote areas where European colonisation occurred much later than elsewhere in Australia. The NT AMI cohorts exhibited a more stable time trend in recent years.

In conclusion, this study demonstrated the long-term trend and ongoing disparity in IHD incidence and survival between Aboriginal and non-Aboriginal populations. Important changes in IHD outcomes were highlighted, including evidence of a plateauing of AMI incidence and continued improvements in survival in Aboriginal population. The results of this study will assist policy makers and healthcare professionals to understand the current and evolving AMI patterns, effectiveness of interventions and the need for continuing investments in both primary and secondary prevention including early detection, active follow-up and management of AMI in regional and remote Australia.

Contributors JRC and SG led the study design. CC, YZ and SL collected hospital and death data, undertook data linkage and statistical analysis, and wrote the first draft of the manuscript. CC, YZ, JRC and SG contributed to the literature review, methodology development, discussion and revision of the manuscript.

Funding The authors have not declared a specific grant for this research from any funding agency in the public, commercial or not-for-profit sectors.

Competing interests None declared.

Patient consent for publication Not required.

Ethics approval The study was approved by the Health Research Ethics Committee of the NT Department of Health and Menzies School of Health Research (2014-2306) and the Australian Institute of Health and Welfare (AlHW, E02015/1/153).

Provenance and peer review Not commissioned; externally peer reviewed.

Data availability statement No data are available. All data relevant to the study are included in the article or uploaded as supplementary information. No additional data are available.

Open access This is an open access article distributed in accordance with the Creative Commons Attribution Non Commercial (CC BY-NC 4.0) license, which permits others to distribute, remix, adapt, build upon this work noncommercially, and license their derivative works on different terms, provided the original work is properly cited, appropriate credit is given, any changes made indicated, and the use is non-commercial. See: http://creativecommons.org/ licenses/by-nc/4.0/.

ORCID iD

Yuejen Zhao http://orcid.org/0000-0002-5775-4503 


\section{REFERENCES}

1 Australian Institute of Health and Welfare. Cardiovascular disease, diabetes and chronic disease - Australian facts: Aboriginal and Torres Strait Islander people. Canberra: AlHW, 2015.

2 Australian Institute of Health and Welfare. Cardiovascular disease, diabetes and chronic kidney disease - Australian facts: prevalence and incidence. Canberra: AlHW, 2014.

3 Australian Institute of Health and Welfare. Cardiovascular disease: Australian facts 2011. Canberra: AlHW, 2011.

4 Australian Bureau of Statistics. Estimates and projections, Aboriginal and Torres Strait Islander Australians, 2001 to 2026. Canberra: ABS, 2014. http://www.abs.gov.au/ausstats/abs@. nsf/Products/02D95BFBCDD976FBCA257CC900143A5B? opendocument

5 You J, Condon JR, Zhao Y, et al. Incidence and survival after acute myocardial infarction in Indigenous and non-Indigenous people in the Northern Territory, 1992-2004. Med J Aust 2009;190:298-302.

6 Ford ES, Capewell S. Proportion of the decline in cardiovascular mortality disease due to prevention versus treatment: public health versus clinical care. Annu Rev Public Health 2011;32:5-22.

7 Australian Institute of Health and Welfare. Australia's health 2018. Canberra: AlHW, 2018. https://www.aihw.gov.au/reports/australiashealth/australias-health-2018/contents/indicators-of-australiashealth/incidence-of-heart-attacks

8 Australian Bureau of statistics. Indigenous status standard. Canberra: ABS, 2014. https://www.abs.gov.au/ausstats/abs@. nsf/Latestproducts/1200.0.55.008Main\%20Features12014,\% 20Version\%201.5? opendocument\&tabname=Summary\&prodno= 1200.0.55.008\&issue=2014,\%20Version\%201.5\&num=\&view $=$

9 Foley M, Zhao Y, Condon J. Demographic data quality assessment for Northern Territory public hospitals, 2011. Darwin: Department of Health, 2012

10 Katzenellenbogen JM, Sanfilippo FM, Hobbs MST, et al. Incidence of and case fatality following acute myocardial infarction in Aboriginal and non-Aboriginal Western Australians (2000-2004): a linked data study. Heart Lung Circ 2010;19:717-25.

11 Dobson AJ, Gibberd RW, Leeder SR. Death certification and coding for ischemic heart disease in Australia. Am J Epidemiol 1983;117:397-405.

12 Weeramanthri T, Connors C, O'Leary S, et al. Chronic disease guidelines and the Indigenous coordinated care trials. Aust Health Rev 2002;25:1-6.
13 Burgess CP, Bailie RS, Connors CM, et al. Early identification and preventive care for elevated cardiovascular disease risk within a remote Australian Aboriginal primary health care service. BMC Health Serv Res 2011;11:24.

14 Teng T-HK, Katzenellenbogen JM, Geelhoed E, et al. Patterns of Medicare-funded primary health and specialist consultations in Aboriginal and non-Aboriginal Australians in the two years before hospitalisation for ischaemic heart disease. Int $J$ Equity Health 2018;17:111.

15 Bradshaw PJ, Alfonso HS, Finn JC, et al. Coronary heart disease events in Aboriginal Australians: incidence in an urban population. Med J Aust 2009;190:583-6.

16 Katzenellenbogen JM, Sanfilippo FM, Hobbs MST, et al. Complex impact of remoteness on the incidence of myocardial infarction in Aboriginal and non-Aboriginal people in Western Australia. Aust $J$ Rural Health 2012;20:305-11.

17 Brown A. Acute coronary syndromes in Indigenous Australians: opportunities for improving outcomes across the continuum of care. Heart Lung Circ 2010;19:325-36.

18 Ong MA, Weeramanthri TS. Delay times and management of acute myocardial infarction in Indigenous and non-Indigenous people in the Northern Territory. Med J Aust 2000;173:201-4.

19 Coory MD, Walsh WF. Rates of percutaneous coronary interventions and bypass surgery after acute myocardial infarction in Indigenous patients. Med J Aust 2005;182:507-12.

20 Australian Institute of Health and Welfare. Trends in coronary heart disease mortality: age groups and populations. Canberra: AlHW, 2014.

21 Davies AJ, Naudin C, Al-Omary M, et al. Disparities in the incidence of acute myocardial infarction: long-term trends from the Hunter region. Intern Med J 2017;47:557-62.

22 Northern Territory Department of Health. Service evaluation framework: cardiology services. Darwin: NTDOH, 2014.

23 Australian Institute of Health and Welfare. Women and heart disease: cardiovascular profile of women in Australia. Canberra: AlHW, 2010.

24 Rollini F, Mfeukeu L, Modena MG. Assessing coronary heart disease in women. Maturitas 2009;62:243-7.

25 Kotwal S, Ranasinghe I, Brieger D, et al. Long-Term outcomes of patients with acute myocardial infarction presenting to regional and remote hospitals. Heart Lung Circ 2016;25:124-31.

26 Australian Institute of Health and Welfare. Trends in Indigenous mortality and life expectancy, 2001-2015: evidence from the enhanced mortality database. Canberra: AlHW, 2014. 